Journal of Engineering and Applied Sciences 14 (10): 3390-3393, 2019

ISSN: 1816-949X

(C) Medwell Journals, 2019

\title{
Bandwidth and Gain Enhancement of Ultra-Wideband Monopole Antenna Using MEBG Structure
}

\author{
Ahmed Jamal Abdullah Al-Gburi, IM Ibrahim, Z. Zakaria and Aymen Dheyaa Khaleel \\ Center for Telecommunication Research and Innovation (CeTRI), \\ Faculty of Electronics and Computer Engineering (FKEKK), \\ Universiti Teknikal Malaysia Melaka (UteM), Durian Tunggal, Melaka, Malaysia
}

\begin{abstract}
Two designed of Ultra-Wide Band (UWB) monopole antenna with/without Electromagnetic Band Gap (MEBG) mushroom structure has been designed and analyzed. EBG structure is used in UWB monopole antenna to enhance the gain and the bandwidth as well, several main parameters of the proposed antenna are discussed such as return loos, gain, radiation pattern. First design of monopole antenna gave the bandwidth without EBG of $8.069 \mathrm{GHz}(2.77-10.84 \mathrm{Ghz})$ while the maximum gain is $4.4 \mathrm{~dB}$. Whereas second design with EBG gives wide huge bandwidth of $23.33 \mathrm{GHz}(2.67-26 \mathrm{GHz})$ and higher maximum gain $5.8 \mathrm{~dB}$. The highest impedance bandwidth attained is $161 \%$ considers VSWR $2: 1$. The proposed antenna will serve different applications such as Bluetooth, cellular systems and satellite communication and $5 \mathrm{G}$. The greater bandwidth also offers the antenna low mutual coupling rather than the antenna without EBG. FR4 substrate is used here with comparative permittivity 4.4. At the end of this study, physical model and measured results are presented and the measured results well match with the simulations.
\end{abstract}

Key words: EBG, ultra-wide-band, monopole antenna, physical mode, UWB, MEBG

\section{INTRODUCTION}

With the startling request for miniaturization of the wireless communication system, antenna design becomes more challenging. Recently monopole antennas have been widely used in satellite communications, aerospace, radars, biomedical Due to its inherent characteristics such as light weight, applications and reflector feeds, low profile, low cost, mechanically robust, integrated circuit compatibility and a highly reliable resonant frequency. Polarization, impedance and pattern. Despite its many advantages, they suffer from disadvantages such as narrow bandwidth, low gain and surface wave excitation., etc. (Liang and Yang, 2007; Islam et al., 2008; Wong, 2002). These inconveniences limit their use in other fields. To overcome the constraints of monopole patch antennas such as narrow bandwidth and low gain, the bandwidth of this antenna can either be improved by optimizing the patch geometry or by using larger substratum thicknesses. Several techniques for such antenna has been initiated to improve performance. One of them, the optimized values for feed and shorting plates are chosen to achieve wideband for a Planar Inverted-F Antenna (PIFA) (Chattha et al., 2009). Another technique for improving bandwidth is the design of a printed monopole antenna with L-shaped slot. With a patch shaped fork (Emadian et al., 2012). However, due to reduced permittivity and thickness of the substrate, the surface wave increases, leading to efficiency, The lower antenna gain and the radiated pattern of the field are also warped. To enhance the antenna performance.

Fairly recently, microstrip antenna and Electromagnetic Band Gap (EBG) structures have attracted Further attention, to high bandwidth with surface doubling. EBG sporadic provisions of dielectric and translucent materials, they have very high impedance and show a band gap to stifle the surface wave current (Zaker and Abdipour, 2011). This will be of various shapes such as fork, fractal, F, sprial, etc. and can be designed even without vias (Verma, 2012).

Various EBG structure (s) techniques are introduced to improve bandwidth such as the use of reversed F-L microstrip patches on the ground with slotted structures. (Verma, 2012), Semi-circular patch and mushroom type ground EBG (Chauhan and Singhal, 2014). Design of a semicircular planar monopole radiator and ground plane together with metamaterial Structures and Artificial Magnetic spiral Conductors (SAMC) (Yang et al., 2005),

Corresponding Author: Ahmed Jamal Abdullah Al-Gburi, Center for Telecommunication Research and Innovation (CeTRI), Faculty of Electronics and Computer Engineering (FKEKK),

Universiti Teknikal Malaysia Melaka (UteM), Durian Tunggal, Melaka, Malaysia 
$2 \times 2$ patch array locate on $\mathrm{EBG}$ spiral type and ground plane spiral type (Madany, 2013). Use of EBG 1-D multilayer structure with large capacity and ground through (Elsheakh et al., 2009). Designing slot monopole antenna with EBG structures. The structures of EBG could be used to improve the gain (Nashaat et al., 2009) and eliminate the interconnection between the array elements (Nashaat et al., 2011; Shen et al., 2014).

In this study, partial ground planes are used as a technique for improving the bandwidth in the monopoly antenna. The bandwidth can extend from $8.069-23.33 \mathrm{GHz}$. In addition, a higher bandwidth increase from 8.069-23.33 $\mathrm{GHz}$ can be obtained by inserting the Electromagnetic Band-Gap (EBG) mushroom type into the original UWB antenna monopoly slot and that's available for most services of wireless communication. The novelty of the methods suggested could be indicated that the bandwidth can be improved without damaging the previous UWB performance and the largest bandwidth of impedance of $156 \%$ can be obtained.

\section{MATERIALS AND METHODS}

Design considerations of the antenna: Figure 1a represents the UWB monopole antenna without EBG. This using CST microwave studio antenna was designed, the material that used for FR-4 substrate board with double side copper conductor. The dielectric constant of substrate is 4.3 with $1.6 \mathrm{~mm}$ of thicknesses and double side copper thicknesses of $0.035 \mathrm{~mm}$ as shown in Fig. 1a the dimensions of rectangular patch with length $20 \mathrm{~mm}$ and width $10 \mathrm{~mm}$, beside it another rectangular patch with length of $18 \mathrm{~mm}$ and width of $5 \mathrm{~mm}$. The ground plane of the original antenna is partial ground with length of $16 \mathrm{~mm}$. This patch is connected by microstrip feed line with length of $17 \mathrm{~mm}$ and width of $3.6 \mathrm{~mm}$. Which is suitable for $50 \Omega$ SMA connector port.

In order to improve bandwidth, the UWB monopole antenna modified with EBG mushroom structure as illustrated in Fig. 1b, consists of the first design antenna monopole antenna modified with EBG mushroom structure which is 32 rectangular EBG mushroom structure that located broadside the microstrip feed line all rectangular EBGs with same dimensions feed line, the width of the $\mathrm{EBG}$ (Web g) is $2.7 \mathrm{~mm}$ and the length (Leb g) is $1.3 \mathrm{~mm}$, the Gap Between the EBGs (GBeb g) is $0.4 \mathrm{~mm}$ with Gap Between Feed line and EBG (GBFeb g) is $0.7 \mathrm{~mm}$ and the Gap inside the EBG cell (Geb g) is 0.8 .

Figure 2 illustrates the fabricated version of UWB monopole antenna with/without EBG mushroom structure. The fabrication process using photoresist method and the antenna soldering with SMA connector.
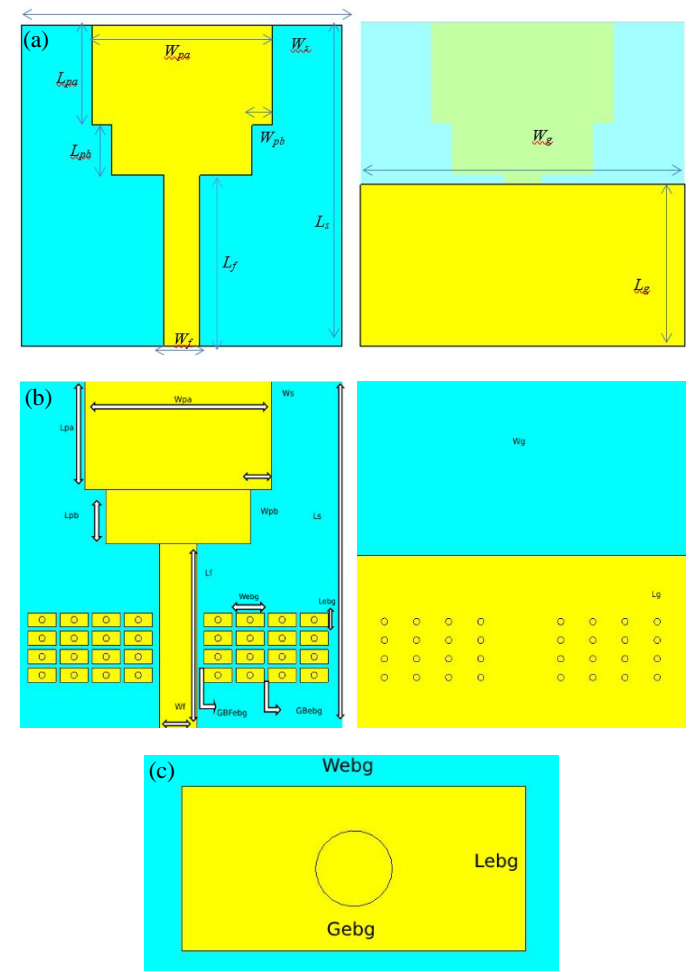

Fig. 1: a) The UWB monopole antenna without EBG mushroom structure $\mathrm{L}_{\mathrm{s}}=\mathrm{W}_{\mathrm{g}}=32, \mathrm{~L}_{\mathrm{g}}=16, \mathrm{~W}_{\mathrm{pa}}=18$, $\mathrm{L}_{\mathrm{pa}}=10, \mathrm{~W}_{\mathrm{pb}}=2$ and $\mathrm{L}_{\mathrm{pa}}=5$; b) With EBG mushroom structure Web $g=2.7$, Leb $g=1.3$, Gbeb g $=0.4$, GBFeb g $=0.7$, Geb g $=0.8$ and e) Unit cell EBG
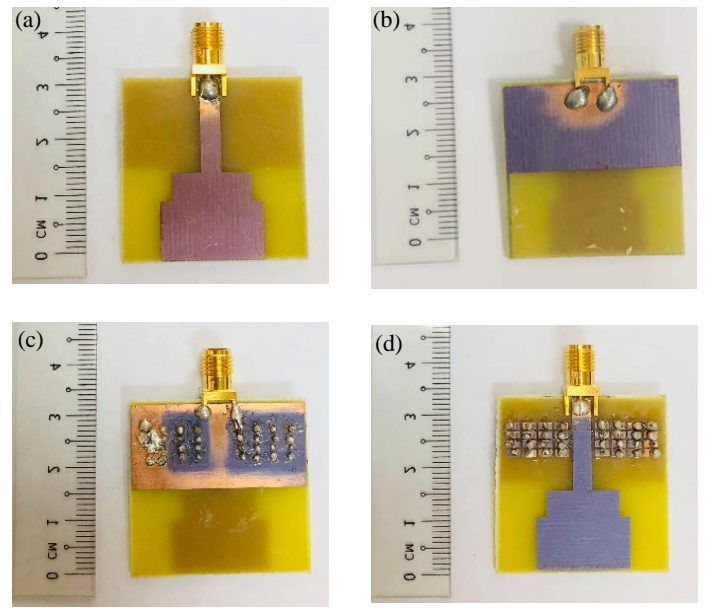

Fig. 2: Fabricated design of the UWB monopole antenna: a) Front view without EBG; b) Back view without EBG; c) Front view with EBG mushroom structure and d) Back view with EBG mushroom structure 


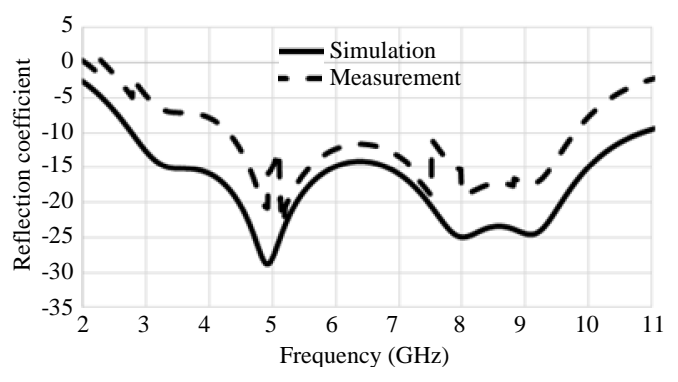

Fig. 3: Simulation and measurement return loss of the UWB monopole antenna without EBG

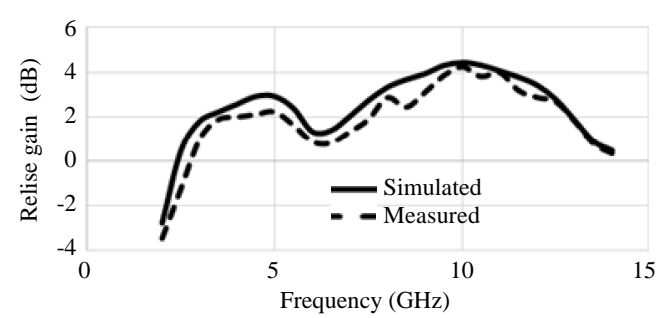

Fig. 4: Antenna gain performance result of UWB monopole antenna without EBG mushroom structure

\section{RESULTS AND DISCUSSION}

In this study by using optimized parameter to obtained better results. The results were carried out using CST microwave studio. Some significant performance outcomes considered for this proposed monopole antenna. These performance outcomes are resonant frequency $(\mathrm{GHz})$, return loss $(\mathrm{dB})$, antenna gain (in $\mathrm{dBi}$ ), $2 \mathrm{D}$ radiation pattern and bandwidth (in $\mathrm{GHz}$ ).

Figure 3 demonstrates the simulated and measured return loss for the UWB monopole antenna without EBG, the antenna operates at range between to $2.77-10.84 \mathrm{GHz}$ and the maximum return loss is $-30 \mathrm{~dB}$. It has the bandwidth of $8.069 \mathrm{GHz}$, the measurement operates at range between $2.81-9.8 \mathrm{GHz}$ and the maximum return loss is $-24 \mathrm{~dB}$. The maximum gain of this antenna is only 4.4 and the measurement gain is about $4.2 \mathrm{~dB}$ as shown in Fig. 4.

Figure 5 shows, the simulated and measured return loss for the EBG mushroom structure UWB monopole antenna. the antenna operates at range between to $\mathrm{GHz}$ $(2.67-26 \mathrm{GHz}) \mathrm{GHz}$ and the maximum return loss is below $-30 \mathrm{~dB}$. It has the bandwidth of $23.33 \mathrm{GHz}$, the measurement operates at range between (3.24-26) GHz has the bandwidth of $19.76 \mathrm{GHz}$ and the maximum gain of this antenna is only $5.8 \mathrm{~dB}$ and the measurement gain is $5 \mathrm{~dB}$ as shown in Fig. 6.

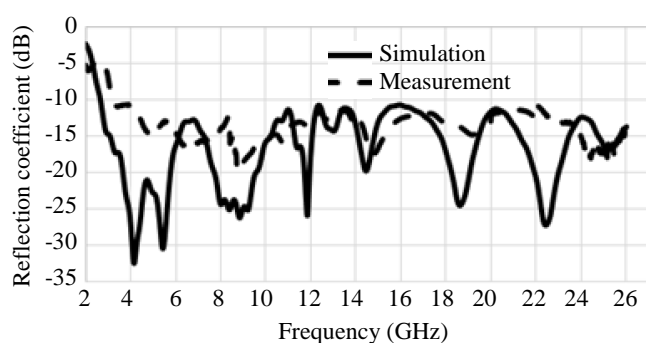

Fig. 5: Simulating and measuring return loss of the UWB monopole antenna with EBG mushroom structure

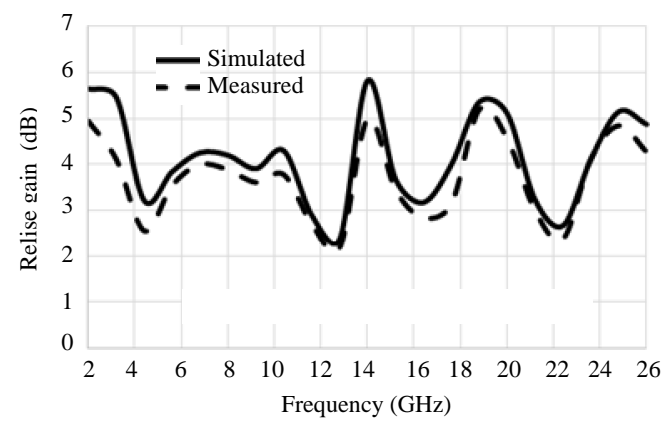

Fig. 6: Antenna gain performance result of the EBG mushroom structure UWB monopole antenna

Table 1: Comparison performance of the UWB monopole antenna without EBG and with EBG

\begin{tabular}{|c|c|c|c|c|}
\hline \multirow[b]{2}{*}{ Variables } & \multicolumn{2}{|l|}{ Without EBG } & \multicolumn{2}{|l|}{ With EBG } \\
\hline & $\begin{array}{l}\text { BW }(\%) \\
\left(f_{2}-f_{1}\right)(G H z)\end{array}$ & $\begin{array}{l}\text { Max gain } \\
(\mathrm{dB})\end{array}$ & $\begin{array}{l}\text { BW }(\%) \\
\left(f_{2}-f_{1}\right)(G H z)\end{array}$ & $\begin{array}{l}\text { Max gain } \\
(\mathrm{dB})\end{array}$ \\
\hline Simulation & $124(2.77-10.84)$ & 4.4 & $161(2.67-26)$ & 5.8 \\
\hline Measurement & $110(2.81-9.8)$ & 4.2 & $155(3.24-26)$ & 5 \\
\hline
\end{tabular}

Table 2: The comparison between this work with published regarding to UWB monopole antenna using EBG structure technique

\begin{tabular}{llll}
\hline References & $\mathrm{BW} \%\left(\mathrm{~F}_{1}-\mathrm{F}_{2}\right)(\mathrm{GHz})$ & Size $(\mathrm{mm})$ & Max gain \\
\hline Guo et al. & $151 \%(1.53-11)$ & $115 \times 60 \times 0.8$ & $3 \mathrm{dBi}$ \\
Li et al. & $66.6 \%(3-6)$ & $60 \times 50 \times 1.5$ & -- \\
Peng et al. & $120 \%(2.74-11)$ & $50 \times 48 \times 1$ & $2.38 \mathrm{dBi}$ \\
This research & $155 \%(3.24-26)$ & $32 \times 32 \times 1.6$ & $5 \mathrm{dBi}$ \\
\hline
\end{tabular}

Table 1 and 2 comparison between this research work with other UWB antenna publications that used EBG structure, this research work shows small antenna size, large bandwidth ranges with higher gain.

\section{CONCLUSION}

In this study UWB monopole antenna with EBG mushroom structure to achieve higher gain and bandwidth without via. two designs simulated and fabricated and they were compared, UWB monopole antenna with EBG mushroom structure applied in various applications such as Bluetooth, mobile and satellite communication systems and $5 \mathrm{G}$, the mushroom monopole 
antenna without EBG cover the range $2.77-10.84 \mathrm{GHz}$ with gain $4.4 \mathrm{~dB}$, give impedance bandwidth of $124 \%$. This specific antenna could be used for some part of UWB application by inserting EBG mushroom structure to increase the bandwidth to higher of $161 \%$ that covers the entire frequency range of $2.67-26 \mathrm{GHz}$ with maximum gain $5.8 \mathrm{~dB}$ that can be used together with satellite communications for Bluetooth, WiMAX, UWB frequency range.

\section{REFERENCES}

Chattha, H.T., Y. Huang and Y. Lu, 2009. PIFA bandwidth enhancement by changing the widths of feed and shorting plates. IEEE. Antennas Wirel. Propag. Lett., 8: $637-640$.

Chauhan, S. and P.K. Singhal, 2014. Comparative analysis of different types of planar EBG Structures. Intl. J. Sci. Res. Publ., 4: 1-6.

Elsheakh, D.N., H.A. Elsadek, E.A. Abdallah, H. Elhenawy and M.F. Iskander, 2009. Enhancement of microstrip monopole antenna bandwidth by using EBG structures. IEEE. Antennas Wirel. Propag. Lett., 8: 959-963.

Emadian, S.R., C. Ghobadi, J. Nourinia, M.H. Mirmozafari and J. Pourahmadazar, 2012. Bandwidth enhancement of CPW-fed circle-like slot antenna with dual band-notched characteristic. IEEE. Antennas Wirel. Propag. Lett., 11: 543-546.

Islam, M.T., M.N. Shakib, N. Misran and B. Yatim, 2008. Analysis of broadband slotted microstrip patch antenna. Proceedings of the 11th International Conference on Computer and Information Technology, December 24-27, 2008, IEEE, Khulna, Bangladesh, ISBN: 978-1-4244-2135-0, pp: 758-761.

Liang, J. and H.Y.D. Yang, 2007. Radiation characteristics of a microstrip patch over an electromagnetic bandgap surface. IEEE. Trans. Antennas Propag., 55: $1691-1697$.
Madany, Y.M., 2013. Bandwidth enhancement of compact UWB microstrip patch antenna using EBG structures. Proceedings of the IEEE Antennas and Propagation Society International Symposium (APSURSI) (Vol. 402), July 7-13, 2013, IEEE Orlando, ISBN:978-1-4673-5315-1, pp: 7-13.

Nashaat, D., H.A. Elsadek, E. Abdallah, H. Elhenawy and M.F. Iskander, 2009. Enhancement of ultra-wide bandwidth of microstrip monopole antenna by using metamaterial structures. Proceedings of the IEEE International Symposium on Antennas and Propagation Society, June 1-5, 2009, IEEE, Charleston, SC, USA., ISBN:978-1-4244-3647-7, pp: $1-4$.

Nashaat, D., H.A. Elsadek, E.A. Abdallah, M.F. Iskander and H.M. Elhenawy, 2011. Ultrawide Bandwidth $2 \times 2$ microstrip patch array antenna using Electromagnetic Band-Gap structure (EBG). IEEE. Trans. Antennas Propag., 59: 1528-1534.

Shen, C.K., T.L. Wu, C.H. Chen and D.H. Han, 2014. Miniaturized and bandwidth-enhanced multilayer 1-D EBG structure for power noise suppression. Proceedings of the IEEE International Symposium on Electromagnetic Compatibility (EMC), August 4-8, 2014, IEEE, Raleigh, NC, USA., ISBN:978-1-4799-5544-2, pp: 357-361.

Verma, A., 2012. EBG Structures and its recent advances in microwave antenna. Intl. J. Sci. Res. Eng. Technol., 1: 084-090.

Wong, K.L., 2002. Compact and Broadband Microstrip Antennas. Wiley, New York, USA., ISBN: 9780471417170, Pages: 344.

Yang, L., M. Fan, F. Chen, J. She and Z. Feng, 2005. A novel compact Electromagnetic-Band Gap (EBG) structure and its applications for microwave circuits. IEEE. Trans. Microwave Theory Tech., 53: $183-190$.

Zaker, R. and A. Abdipour, 2011. Bandwidth enhancement and miniaturization of fork-shaped monopole antenna. IEEE. Antennas Wirel. Propag. Lett., 10: 697-700. 